\title{
Hydrothermal synthesis and performance of Co doped lithiated vanadium oxides as cathode material for lithium ion batteries
}

\author{
Zhou Zou, Changlei Liu, Xinyu Jiang, Jinhua Luo, Xin Wang and Jijun Feng*
}

Key Laboratory of Chemical Sensing \& Analysis in Universities of Shandong, School of Chemistry and Chemical Engineering, University of Jinan, Jinan 250022, China

alab_feng@163.com

Keywords: Lithium ion batteries; Cathode material; Hydrothermal synthesis; $\mathrm{LiV}_{3} \mathrm{O}_{8}$; Doping

Abstract. Co doped lithiated vanadium oxides $\mathrm{LiV}_{3-x} \mathrm{Co}_{x} \mathrm{O}_{8}$ as promising cathode material for lithium ion batteries are prepared with a hydrothermal process. The crystalline phase are characterised by powder X-ray diffraction and the morphology are observed by scanning electron microscope. The electrochemical properties of synthesized samples are investigated by galvanostatic charge and discharge at a current density of $50 \mathrm{~mA} \mathrm{~g}^{-1}$. The electrochemical properties were greatly improved via $\mathrm{Co}$ doping. Among the doping modified material $\mathrm{LiV}_{3-x} \mathrm{Co}_{x} \mathrm{O}_{8}$, the most excellent performance can be achieved when $x=0.01$ and 0.03 , which keep a specific discharge capacity of about $146 \mathrm{mAh} \mathrm{g}^{-1}$ even after 40 cycles.

\section{Introduction}

The layered $\mathrm{LiCoO}_{2}$ has been the dominating cathode material for commercial lithium ion cells in the decade or so since its facility to manufacture and good cycling behaviour. But only $50 \%$ of its theoretical capacity could be utilized in practical cells due to chemical and structural instabilities at deep charge ${ }^{[1]}$. Moreover, $\mathrm{Co}$ is expensive and relatively toxic, and charged $\mathrm{Li}_{1-x} \mathrm{CoO}_{2}$ poses safety concerns. These difficulties have generated enormous interest in the development of alternative cathode materials. In this regard, cation-substituted spinel manganese oxides $\mathrm{LiMn}_{2} \mathrm{O}_{4}{ }^{[3-5]}$, conductive carbon incorporated olivine iron phosphate $\mathrm{LiFePO}_{4}{ }^{[6,7]}$ and layered oxide solid solutions $\mathrm{LiMn}_{\mathrm{x}} \mathrm{Ni}_{\mathrm{x}} \mathrm{Co}_{1-2 \mathrm{x}} \mathrm{O}_{2}{ }^{[8,9]}$ are being intensively pursued continuously. These are safer and potentially cheaper than $\mathrm{LiCoO}_{2}$. However, it is a perception that there is little scope for further increases in capacity with the existing cathode materials. Vanadium oxides are attractive alternatives as vanadium is known to exist in a wide range of oxidation states from +2 as in $\mathrm{VO}$ to +5 as in $\mathrm{V}_{2} \mathrm{O}_{5}$ leading to the attractive potential of vanadium oxides to offer much higher capacities. Among the various known vanadium oxides, $\mathrm{LiV}_{3} \mathrm{O}_{8}$ have been found to show interesting cathode properties. $\mathrm{LiV}_{3} \mathrm{O}_{8}$ has a layered structure where pre-existing $\mathrm{Li}^{+}$ions at octahedral sites attach adjacent layers strongly. Over three equivalents of $\mathrm{Li}^{+}$ions can be inserted / extracted in $\mathrm{Li}_{1+x} \mathrm{~V}_{3} \mathrm{O}_{8}$ reversibly because of both the outstanding structural stability and empty sites for $\mathrm{Li}^{+}$ion occupation between the layers.

Critical to the success of new cathode materials, is their preparation, which controls the morphology, particle size and cation order amongst other critical parameters ${ }^{[10]}$. Although traditionally high temperature methods have been widely used for their simpleness, they are both energy intensive and cannot readily produce many potentially metastable structures that might result in high lithium ion diffusivity. Soft chemical approaches, such as hydrothermal/solvothermal or coprecipitation methods offer many advantages. In this work, a serials of $\mathrm{Co}$ doped $\mathrm{LiV}_{3} \mathrm{O}_{8}$ have been synthesized via a hydrothermal process. The crystal structure of $\mathrm{LiV}_{3-x} \mathrm{Co}_{x} \mathrm{O}_{8}(x=0,0.01,0.03,0.05,0.08,0.10)$ were refined by powder X-ray diffraction and the micromorphology was characterized using scanning electron microscopy. By performing the galvanostatically charge and discharge experiments, their electrochemical properties were systematically compared and investigated. 


\section{Experimental}

Materials preparation

Analytically pure $\mathrm{LiOH} \cdot \mathrm{H}_{2} \mathrm{O}, \mathrm{V}_{2} \mathrm{O}_{5}, \mathrm{CoCl}_{2} \cdot 6 \mathrm{H}_{2} \mathrm{O}$ and $\mathrm{NH}_{3} \cdot \mathrm{H}_{2} \mathrm{O}$ were used as raw materials without any purification. Stoichiometrical $\mathrm{LiOH} \cdot \mathrm{H}_{2} \mathrm{O}, \mathrm{V}_{2} \mathrm{O}_{5}$ and $\mathrm{CoCl}_{2} \cdot 6 \mathrm{H}_{2} \mathrm{O}$ were weighed and mixed in deionized water followed by ammonia (1:10) adding slowly to adjust the $\mathrm{pH}$ value to 9 with magnetic stirring and heating in water bath. The obtained dark green solution was then transferred into a $50 \mathrm{ml}$ Teflon lined autoclave. The autoclave was sealed, and heated at $160{ }^{\circ} \mathrm{C}$ for $16 \mathrm{~h}$. After hydrothermal treatment, a colorless clear solution was obtained in which $\mathrm{pH}$ decreased to 7 . The solution was dried in air at $100{ }^{\circ} \mathrm{C}$ to evaporate the water. The precursor was then heat-treated at 300 ${ }^{\circ} \mathrm{C}$ for $12 \mathrm{~h}$. After natural cooling in the furnace, the dark brown products were finally gained.

Characterization of samples

The X-ray diffraction (XRD) analysis was operated on Bruker AXS D8 Advance X-Ray Diffractometer with $\mathrm{CuK} \alpha$ radiation in the $2 \theta$ range of $10-80^{\circ}$ to identify the crystalline phase of synthesized $\mathrm{LiV}_{3} \mathrm{O}_{8}$ powders. Morphology of the samples was observed on the Hitachi S-2500 Scanning Electron Microscope.

Electrochemical experiments were operated on CR2032 coin cells with Lithium metal pellets as negative electrodes, using $1 \mathrm{M} \mathrm{LiPF}_{6}$ in $\mathrm{EC}+\mathrm{DMC}$ (1:1 volume ratio) as electrolytes and Celgard 2300 membrane as separators. The cathodes were prepared by mixing $80 \%$ active material with $12 \%$ acetylene black and $8 \%$ polytetrafluoroethylene. The mixture was ultrasonic-mixed with ethanol as dispersant. The as-prepared slurry was then coated onto an aluminum foil and vacuum dried at $120{ }^{\circ} \mathrm{C}$ for 12h. All cells were assembled in an argon-filled glove box (Mikrouna Super 1220/750/900). The galvanostatically charge-discharge tests were performed on PCBT-138-32D battery program-control test system with a mass current density of $50 \mathrm{~mA} \mathrm{~g}^{-1}$ between the potential limits of 1.5-4.0V (vs. $\left.\mathrm{Li} / \mathrm{Li}^{+}\right)$.

\section{Results and discussion}

Crystal structure

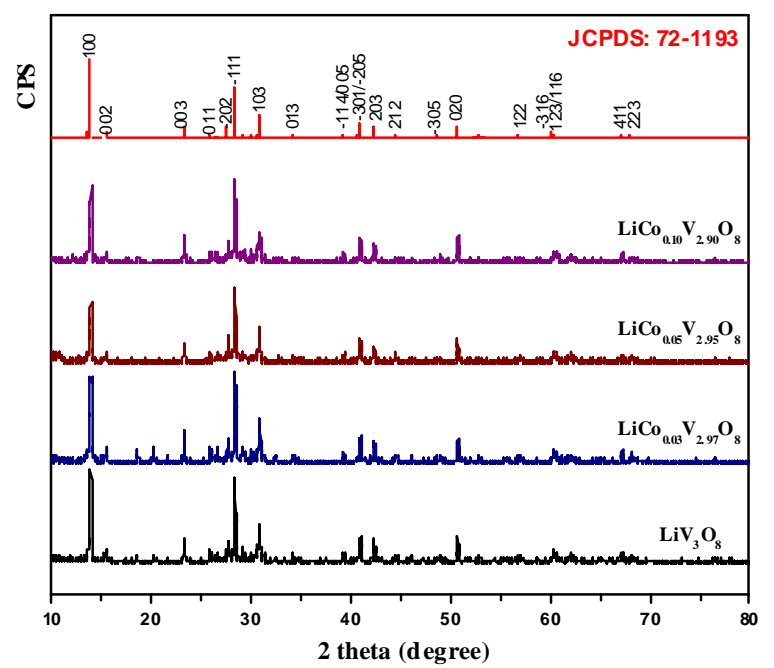

Fig. 1. XRD patterns of $\mathrm{LiCo}_{x} \mathrm{~V}_{3-x} \mathrm{O}_{8}$ powders

The XRD patterns of $\mathrm{LiV}_{3-x} \mathrm{Co}_{x} \mathrm{O}_{8}(x=0,0.03,0.05,0.10)$ are shown in Fig. 1. The XRD patterns indicate that all samples are identified as single-phase layered structures corresponding to the $\mathrm{LiV}_{3} \mathrm{O}_{8}$ (JCPDS: 72-1193). The $\mathrm{LiV}_{3} \mathrm{O}_{8}$ has monoclinic crystalline and belongs to the $\mathrm{P} 2_{1} / \mathrm{m}$ space group. It is composed of two basic structural units, namely, a $\mathrm{VO}_{6}$ octahedron and a $\mathrm{VO}_{5}$ distorted trigonal bipyramids. According to the XRD patterns, the decreased diffraction intensity and widen peaks with lager values of full width at half peak (FWHP) indicate the crystallinity decline with the increasing doping concentration. The XRD patterns exhibit that all the $\mathrm{LiV}_{3-x} \mathrm{Co}_{x} \mathrm{O}_{8}$ samples have shifts of the $2 \theta$ 
of the $\{100\}$ peak to larger values in contrast with the pristine $\mathrm{LiV}_{3} \mathrm{O}_{8}$. It is also noteworthy that the Co doped materials have much smaller $d_{(100)}$ values than the undoped $\mathrm{LiV}_{3} \mathrm{O}_{8}$. The small $d_{(100)}$ value lead to relatively short diffusion paths for the lithium ions inserted between these planes. Therefore, the improved electrochemical performance should be expected for the $\mathrm{LiV}_{3-x} \mathrm{Co}_{x} \mathrm{O}_{8}$ cathodes.

\subsection{Morphology}

Fig. 2 shows the morphology of hydrothermal synthesized $\mathrm{LiV}_{3} \mathrm{O}_{8}$ in different magnification from $1 \mathrm{~K} \times$ to $7 \mathrm{~K} \times$. It can be seen that the sample consists of agglomerations of widely dispersed small particles. In Fig. 2(C) we can clearly see submicron-sized plate-like particles with agglomeration. It has been reported that the intercalation process of $\mathrm{Li}^{+}$ion between the layers of cathode material is a diffusion process ${ }^{[11]}$. Therefore the larger grains would lead to a long path for $\mathrm{Li}^{+}$ion, which are disadvantageous to intercalation. By contrast, the floppy morphology with smaller grains is beneficial to lithium-ion intercalation and deintercalation, leading to better electrochemical performance.
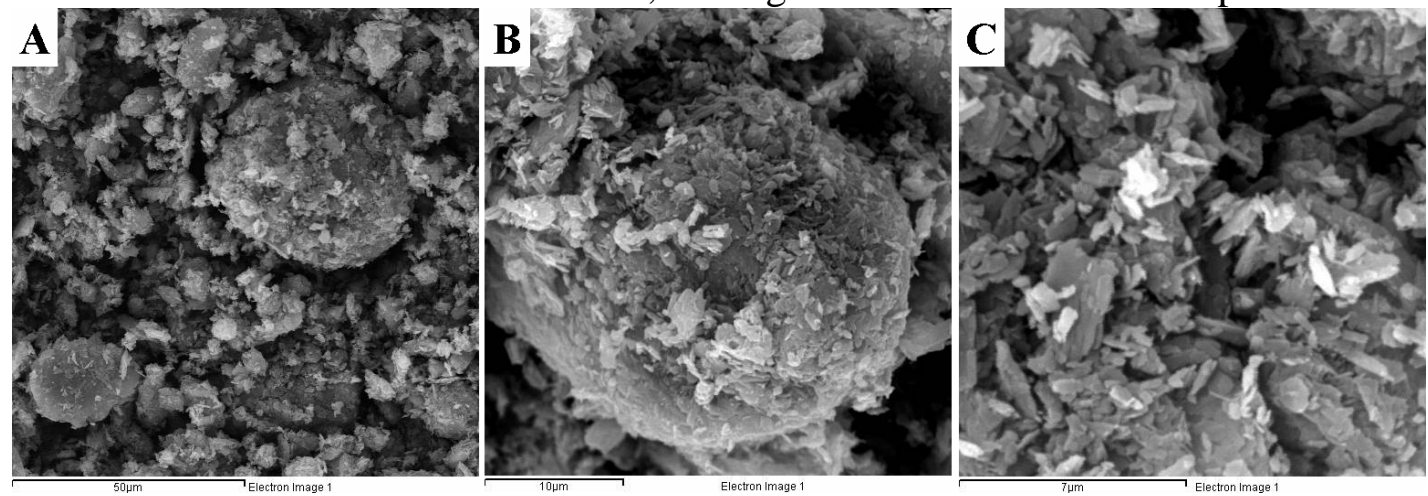

Fig. 2. SEM images of hydrothermal synthesized $\mathrm{LiV}_{3} \mathrm{O}_{8}$ in different magnification $(\mathrm{A}$ : in $1 \mathrm{~K} \times$; $\mathrm{B}$ : in $3 \mathrm{~K} \times$; $\mathrm{C}:$ in $7 \mathrm{~K} \times)$

Electrochemical performance

The first discharge curves and cycling stability curves of $\mathrm{LiV}_{3-x} \mathrm{Co}_{x} \mathrm{O}_{8}(x=0,0.01,0.03,0.05,0.08$, 0.10) were illustrated in Fig. 3. It can be seen in Fig. 3A that the Co doped lithium trivanadate cathodes take on smaller initial capacities than the pristine $\mathrm{LiV}_{3} \mathrm{O}_{8}$. With the doping concentration increased, the inicial capacity declined from $281.65 \mathrm{mAh} \mathrm{g}^{-1}$ of $\mathrm{LiV}_{3} \mathrm{O}_{8}$ to $231.12 \mathrm{mAh} \cdot \mathrm{g}^{-1}$ of $\mathrm{LiV}_{2.90} \mathrm{Co}_{0.10} \mathrm{O}_{8}$.
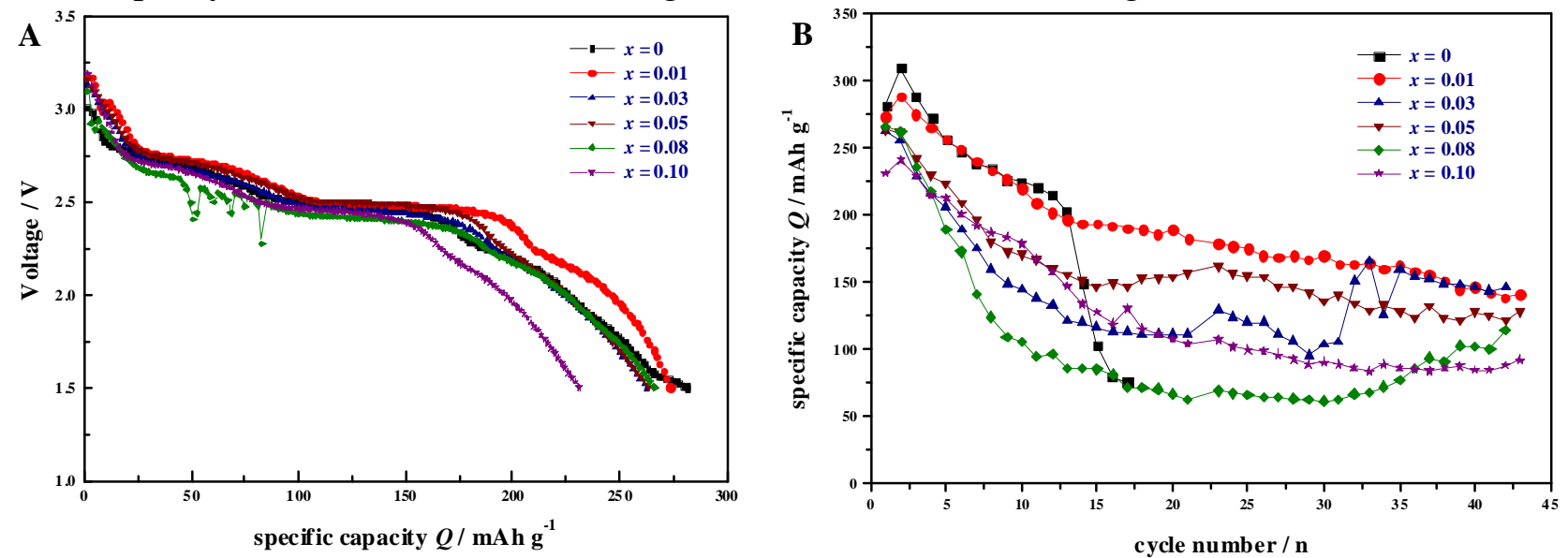

Figure 3. A: Initial discharge and B: cycling stability curves of $\mathrm{LiCo}_{x} \mathrm{~V}_{3-x} \mathrm{O}_{8}$

The cycle performance of $\mathrm{LiV}_{3-x} \mathrm{Co}_{x} \mathrm{O}_{8}(x=0,0.01,0.03,0.05,0.08,0.10)$ were shown in Fig. 3B. It can be easily seen from Fig. 3B that remarkably improved cycle performance can be achieved via Co doping. The undoped $\mathrm{LiV}_{3} \mathrm{O}_{8}$ shows a rapid capacity fading after 13 cycles. This may due to the breakdown of the insertion-extraction channels. By contrast, all the doped $\mathrm{LiV}_{3-x} \mathrm{Co}_{x} \mathrm{O}_{8}$ cathodes can cycle stably. Among them, $\mathrm{LiV}_{2.99} \mathrm{Co}_{0.01} \mathrm{O}_{8}$ has the most excellent cycle ability, which can preserve a special capacity of $146 \mathrm{mAh} \mathrm{g}^{-1}$ even after 40 cycles. $\mathrm{LiV}_{2.97} \mathrm{Co}_{0.03} \mathrm{O}_{8}$ show a severe capacity decline in the first 30 cycles, but it recovered to a higher level after that and can also present a special capacity of about $146 \mathrm{mAh} \mathrm{g}^{-1}$ after 40cycles. 
When $x=0.05,0.08$ and 0.10 , the special capacities remain $128 \mathrm{mAh} \mathrm{g}^{-1}, 101 \mathrm{mAh} \mathrm{g}^{-1}$ and $85 \mathrm{mAh}$ $\mathrm{g}^{-1}$ respectively after 40 cycles. Furthermore, the $\mathrm{LiV}_{3-x} \mathrm{Co}_{x} \mathrm{O}_{8}$ cathodes, with $x$ in the range of 0.01 to 0.10 , all kept good charge-discharge efficiency.

\section{Conclusions}

A hydrothermal method was employed to synthesize $\mathrm{LiV}_{3-x} \mathrm{Co}_{x} \mathrm{O}_{8}$ with $x$ in the range of $0 \leq x \leq 0.10$. All samples are identified as single-phase layered structures consistent with the $\mathrm{LiV}_{3} \mathrm{O}_{8}$. Co doped lithiated vanadium oxides cathodes show obviously improved cycle reversibility compared to the pristine $\mathrm{LiV}_{3} \mathrm{O}_{8}$. Among the doped materials, $\mathrm{LiV}_{2.99} \mathrm{Co}_{0.01} \mathrm{O}_{8}$ sand $\mathrm{LiV}_{2.97} \mathrm{Co}_{0.03} \mathrm{O}_{8}$ take on excellent cycle ability keeping a special capacity of $146 \mathrm{mAh} \mathrm{g}^{-1}$ after 40 cycles. The doped materials also show excellent reversibility with high charge-discharge efficiency during cycles. The Co doping modified lithium trivanadate cathodes are promising for application in lithium ion batteries.

\section{Acknowledgements}

This work was financially supported by Natural Science Foundation of China (No. 51102114, 21201079) and Sci-Tech Development Project of Jinan (No. 201401234).

\section{References}

[1] C. R. Jarvis, M .J. Lain, Y. Gao, M. Yakovleva: J. Power Sources. Vol.146 (2005), p. 331

[2] A. M. Kannan, A. Manthiram: J. Power Sources. 159 (2006), p. 1405

[3] B. Qin, Z. Liu, G. Ding, et al. Electrochimica Acta. 141(2014), p. 167

[4] J. J. Feng, R. Q. Xu, Z.Y. Tang, H. Q. Ai: Chem. J. Chinese University. 28(2007), p. 1532

[5] S. Zhao, Q. Chang, K. Jiang, et al. Solid State Ionics. 253(2013), p. 1

[6] K. Hamamoto, M. Fukushima, M. Mamiya, et al. Solid State Ionics. 225(2012), p. 560

[7] P. P. Prosini, M. Carewska, C. Cento, A. Masci: Electrochimica Acta. 150(2014), p. 129

[8] K. Karthikeyan, S. Amaresh, S. H. Kim, et al. Electrochimica Acta. 108(2013), p. 749

[9] L. Li, X. Li, Z. Wang, et al. Powder Technol. 206(2011). p. 353

[10] J. Feng, X. Liu, X. Zhang, et al. J. Electrochem. Soc. 156(2009), p. A768

[11] K. Nassau, D. W. Murphy. J. of Non-Crystalline Solids. 44(1981), p. 297 